\title{
Plasma etching for the compatibility of thin film metallic coatings and direct bonding of silicon pore optics
}

Girou, D.; Massahi, S.; Ferreira, D. D. M.; Christensen, F. E.; Landgraf, B.; Shortt, B.; Collon, M.; Beijersbergen, $M$.

Published in:

Journal of Applied Physics

Link to article, DOI:

$10.1063 / 5.0010212$

Publication date:

2020

Document Version

Publisher's PDF, also known as Version of record

Link back to DTU Orbit

Citation (APA):

Girou, D., Massahi, S., Ferreira, D. D. M., Christensen, F. E., Landgraf, B., Shortt, B., Collon, M., \&

Beijersbergen, M. (2020). Plasma etching for the compatibility of thin film metallic coatings and direct bonding of silicon pore optics. Journal of Applied Physics, 128(9), [095302]. https://doi.org/10.1063/5.0010212

\section{General rights}

Copyright and moral rights for the publications made accessible in the public portal are retained by the authors and/or other copyright owners and it is a condition of accessing publications that users recognise and abide by the legal requirements associated with these rights.

- Users may download and print one copy of any publication from the public portal for the purpose of private study or research.

- You may not further distribute the material or use it for any profit-making activity or commercial gain

- You may freely distribute the URL identifying the publication in the public portal 


\section{Plasma etching for the compatibility of thin film metallic coatings and direct bonding of silicon pore optics}

Cite as: J. Appl. Phys. 128, 095302 (2020); https://doi.org/10.1063/5.0010212

Submitted: 08 April 2020 . Accepted: 22 August 2020 . Published Online: 04 September 2020

D. Girou (D), S. Massahi (D), D. D. M. Ferreira (D, F. E. Christensen (D), B. Landgraf, B. Shortt, M. Collon (D), and $\mathrm{M}$. Beijersbergen

\section{ARTICLES YOU MAY BE INTERESTED IN}

Progress on and challenges of p-type formation for GaN power devices

Journal of Applied Physics 128, 090901 (2020); https://doi.org/10.1063/5.0022198

Experimental and theoretical study of capacitive memory of metal-oxide-semiconductor devices based on Er-doped $\mathrm{In}_{2} \mathrm{O}_{3}$ nano-column arrays

Journal of Applied Physics 128, 095704 (2020); https://doi.org/10.1063/5.0013904

$\mathrm{Mo} / \mathrm{Ti}$ multilayer Bragg reflector for $\mathrm{LiNbO}_{3}$ film bulk acoustic wave resonators

Journal of Applied Physics 128, 094503 (2020); https://doi.org/10.1063/5.0011954

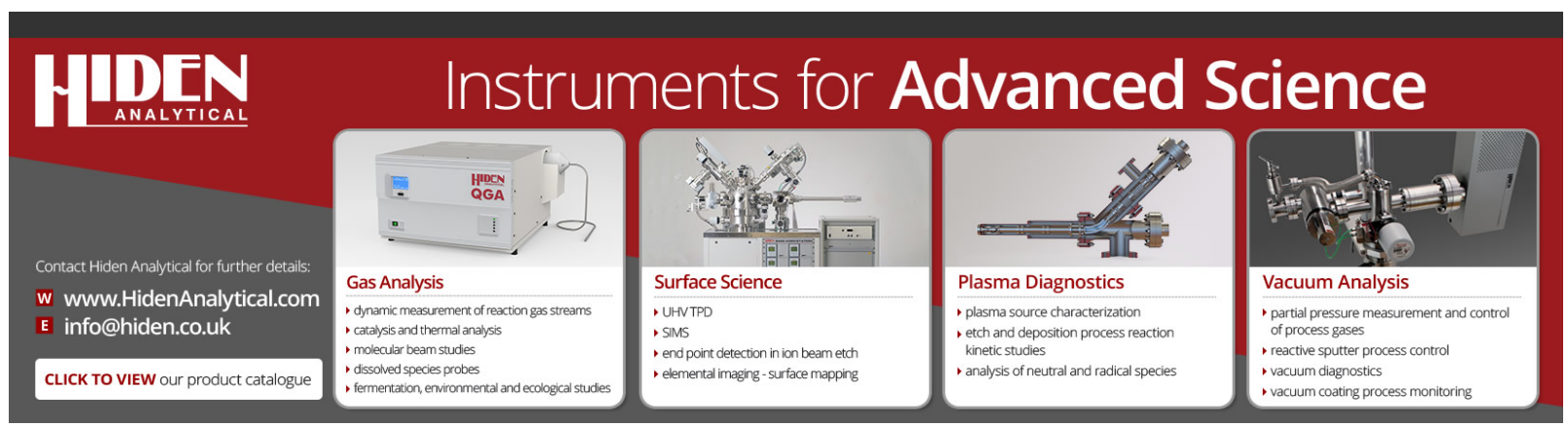




\title{
Plasma etching for the compatibility of thin film metallic coatings and direct bonding of silicon pore optics
}

Cite as: J. Appl. Phys. 128, 095302 (2020); doi: 10.1063/5.001 0212

Submitted: 8 April 2020 - Accepted: 22 August 2020 .

Published Online: 4 September 2020

D. Girou, ${ }^{1, a), b)}$ (D) S. Massahi, ${ }^{2}$ (D) D. D. M. Ferreira, ${ }^{2}$ (D) F. E. Christensen, ${ }^{2}$ (D) B. Landgraf, ${ }^{1}$ B. Shortt, ${ }^{3}$ M. Collon, ${ }^{1}$ and M. Beijersbergen ${ }^{7, b)}$

\author{
AFFILIATIONS \\ ${ }^{1}$ cosine measurement systems, Oosteinde 36, $2361 \mathrm{HE}$ Warmond, The Netherlands \\ ${ }^{2}$ DTU Space, Technical University of Denmark, Elektrovej 327, 2800 Kgs. Lyngby, Denmark \\ ${ }^{3}$ European Space Agency, ESTEC, Keplerlaan 1, 2200 AG Noordwijk, The Netherlands

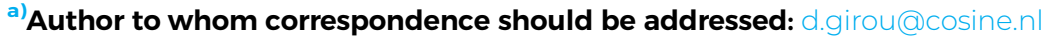

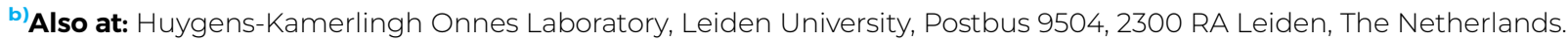

\begin{abstract}
Silicon pore optics are a new type of high-performance $\mathrm{x}$-ray optics designed to enable future space-borne $\mathrm{x}$-ray observatories such as European Space Agency's Athena. These optics will make it possible to build telescopes with effective areas of the order of a few square meters and angular resolutions better than $5 \mathrm{~s}$ of arc. During manufacturing of the optics, thin film metallic coatings are sputtered onto mirror plates to help achieve this large effective area. Then, these plates are stacked on top of each other using direct silicon bonding to achieve the shape of an approximate Wolter type-I telescope design. It is, therefore, necessary to verify the compatibility of the coating and bonding processes. We observe the unintentional removal of coatings on silicon pore optics plates after their wet chemical activation, a step required to make direct bonding possible. In this paper, we investigate plasma etching prior to thin film deposition as a solution to this problem. First, we ensure that plasma etching does not impact the low surface roughness required to achieve high imaging performance. Then, we demonstrate that plasma etching before thin film deposition prevents unintentional removal of the metallic coatings during the activation step, making coating deposition compatible with direct bonding of silicon pore optics plates.
\end{abstract}

Published under license by AIP Publishing. https://doi.org/10.1063/5.0010212

\section{INTRODUCTION}

High-sensitivity observations in the $\mathrm{x}$-ray band are needed to improve the understanding of high-energy phenomena of all classes of astrophysical objects, from large-scale hot gas structures to compact objects such as black holes. For example, observing the $\mathrm{x}$-ray emitting plasma of the intra-cluster medium would shed light on how hot baryons accrete and evolve. ${ }^{1}$ Also, detecting x-ray emissions from accreting super massive black holes with a high redshift $(z>6)$ could reveal the processes responsible for their early growth as well as their influence on larger scales in the early universe. $^{2-4}$

Observing with high sensitivity depends partly on large throughput and, therefore, on a large collecting area. Because $\mathrm{x}$-ray focusing telescopes use grazing incidence angles, the collecting area is only a fraction of the actual surface area of the x-ray mirrors. Moreover, the collecting area of a telescope is reduced to a smaller effective area due, for instance, to reflectivity and scattering losses.

Silicon pore optics (SPO) are a new type of x-ray optics designed to enable future space-borne $\mathrm{x}$-ray observatories such as Athena. ${ }^{5}$ They are being developed by the European Space Agency (ESA) in collaboration with academic and industrial partners. ${ }^{6,7}$ These high-performance, modular, lightweight yet stiff, highresolution $\mathrm{x}$-ray optics shall allow missions to reach an unprecedented large effective area of a few square meters, operating in the $0.2-12 \mathrm{keV}$ band and with an angular resolution aiming at being better than $5 \mathrm{arcsec}$. To this end, custom-made assembly tools and processes have been developed to build SPO using direct silicon bonding. ${ }^{8,9}$ SPO plates are single-sided ribbed rectangular silicon 


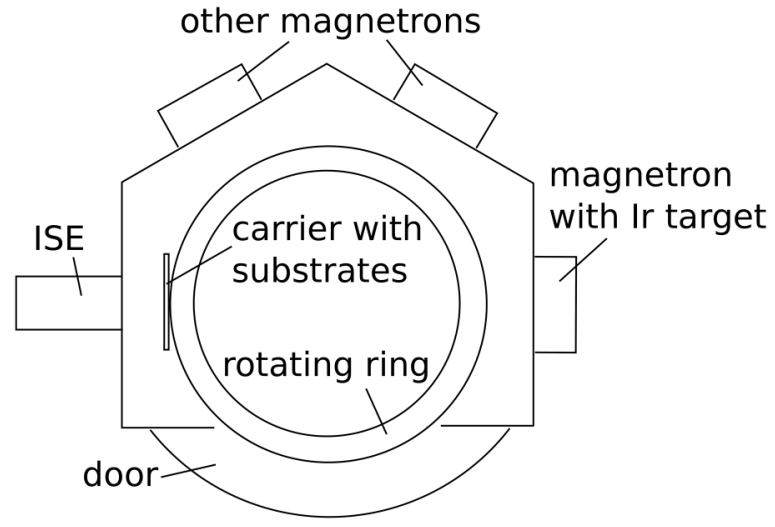

(a)

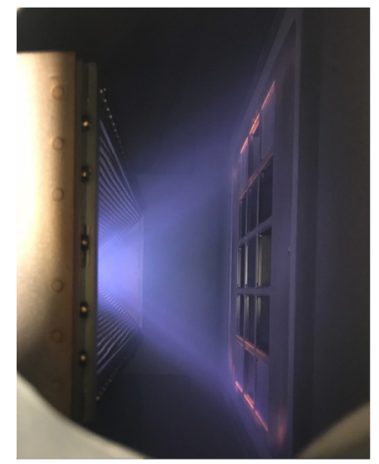

(b)

FIG. 1. Views of the coating chamber from above. (a) Schematic view displaying the position of the inverse sputter etcher (ISE) compared to the iridium target and its magnetron. The carriers holding the substrates are mounted on a rotating ring passing by the ISE and the iridium target successively. Note that two additional magnetrons are available in the chamber and that a door is used to load and unload the carriers. (b) Discharge plasma glow of the ISE. The ISE is visible on the left of the picture and the carriers with the substrates on the right. substrates assembled into high-performance optics by directly bonding them on top of each other. On the ribbed side of each plate, the bonding areas are the bottom surfaces of the ribs, while on the non-ribbed side, the bonding areas are the surfaces matching the ribs. Direct silicon bonding is key to controlling the shape of the approximated paraboloid and hyperboloid shapes of Athena's Wolter type-I telescope design. ${ }^{10}$

As the development of SPO progresses, it is necessary to validate the direct bonding process with the metallic coating deposition process needed for the observatory to achieve a large effective area. ${ }^{11}$ The coating deposition process consists of sputtering thin films of metals onto the non-ribbed side of an SPO plate, while a patterned photoresist layer prevents the coating from depositing onto the bonding surfaces. The photoresist is then lifted off chemically, and the bonding surfaces are cleaned using an RCA recipe ${ }^{12}$ (SC-1 cleaning only). Previous studies observed unintentional removal of metallic thin films on SPO after the wet chemical cleaning step required for the direct bonding and indicated that molecular contamination originating from the ambient as well as from fabrication processes such as photoresist remnants might be the cause. ${ }^{13}$ Surface treatment is, therefore, considered to provide clean surfaces prior to thin film deposition and reduce coating surface defects. An inverse sputter etcher (ISE) unit has been implemented in the DC magnetron sputtering machine dedicated for the SPO production. ${ }^{14}$ After photoresist deposition, this ISE allows for plasma cleaning of the substrate surfaces in situ, before thin film deposition. This way, vacuum is maintained between the plasma etching and coating processes, preventing the substrates to be exposed to the atmosphere. The etching process is performed by bombarding the SPO plate surface with a mixture of argon and oxygen ions. Possible organic contamination and photoresist residuals are removed either by elastic scattering or chemical reactions. However, a potential down-side of the process can be an increase in surface roughness by surface modification due to the ion bombardment. ${ }^{15,16}$

In this paper, we present the results of a study on the effect of plasma etching on SPO plates. We first investigated the possible change in surface roughness with atomic force microscope (AFM) measurements of the plasma etched surfaces. Then, we derived the

TABLE I. AFM results of nine non-patterned, non-coated SPO plates before and after plasma etching. The plasma discharge power and exposure time vary per substrate. The AFM measurements were performed in the center of each substrate with scan sizes of $1 \times 1 \mu \mathrm{m}^{2}$ and $20 \times 20 \mu \mathrm{m}^{2}$, respectively.

\begin{tabular}{|c|c|c|c|c|c|c|}
\hline Substrate id & $\begin{array}{c}\text { Discharge } \\
\text { power } \\
(\mathrm{W})\end{array}$ & $\begin{array}{l}\text { Exposure } \\
\text { time } \\
(\mathrm{s})\end{array}$ & $\begin{array}{c}\text { rms before plasma } \\
(\mathrm{nm}) \\
1 \times 1 \mu \mathrm{m}^{2}\end{array}$ & $\begin{array}{c}\text { rms before plasma } \\
\text { (nm) } \\
20 \times 20 \mu \mathrm{m}^{2}\end{array}$ & $\begin{array}{c}\text { rms after plasma } \\
(\mathrm{nm}) \\
1 \times 1 \mu \mathrm{m}^{2}\end{array}$ & $\begin{array}{c}\text { rms after plasma } \\
(\mathrm{nm}) \\
20 \times 20 \mu \mathrm{m}^{2}\end{array}$ \\
\hline $532-10$ & 100 & 120 & 0.25 & 0.20 & 0.24 & 0.19 \\
\hline $537-10$ & 100 & 240 & 0.25 & 0.21 & 0.23 & 0.20 \\
\hline 590-12 & 100 & 360 & 0.28 & 0.21 & 0.23 & 0.21 \\
\hline 590-13 & 450 & 120 & 0.29 & 0.27 & 0.24 & 0.21 \\
\hline 548-10 & 450 & 240 & 0.25 & 0.23 & 0.22 & 0.21 \\
\hline $635-06$ & 450 & 360 & 0.25 & 0.22 & 0.23 & 0.22 \\
\hline $638-02$ & 800 & 120 & 0.27 & 0.24 & 0.21 & 0.22 \\
\hline $692-12$ & 800 & 240 & 0.26 & 0.23 & 0.23 & 0.23 \\
\hline $638-15$ & 800 & 360 & 0.28 & 0.27 & 0.23 & 0.24 \\
\hline
\end{tabular}


TABLE II. Parameters for the sputter deposition of $10 \mathrm{~nm}$ of iridium.

\begin{tabular}{lc}
\hline \hline Maximum base pressure & $2.0 \times 10^{-6} \mathrm{mbar}$ \\
Working gas pressure & $3.4 \times 10^{-3} \mathrm{mbar}$ \\
Power density & $3.1 \mathrm{~W} \mathrm{~cm}$ \\
Target-to-substrate distance & $105.0 \mathrm{~mm}$ \\
\hline \hline
\end{tabular}

most suitable plasma etching parameters on SPO plates without a photoresist layer. Finally, we validated the plasma etching within the coating process on SPO plates with photoresist and proved that it is now compatible with the subsequent bonding step.

\section{EVALUATING THE IMPACT OF PLASMA ETCHING ON SURFACE ROUGHNESS}

SPO plate surfaces must have a low root-mean-square (rms) roughness (less than approximatively $0.5 \mathrm{~nm}$ ) to achieve high imaging performance. ${ }^{17-19}$ Therefore, the first objective is to ensure plasma etching does not increase the surface rms roughness by surface modification due to ion bombardment. For this purpose, we performed AFM measurements on nine non-patterned (without photoresist) SPO plates before and after the plasma etching process.

For the plasma etching, the substrates were mounted onto carriers in the coating chamber, as illustrated in Fig. 1, and exposed to

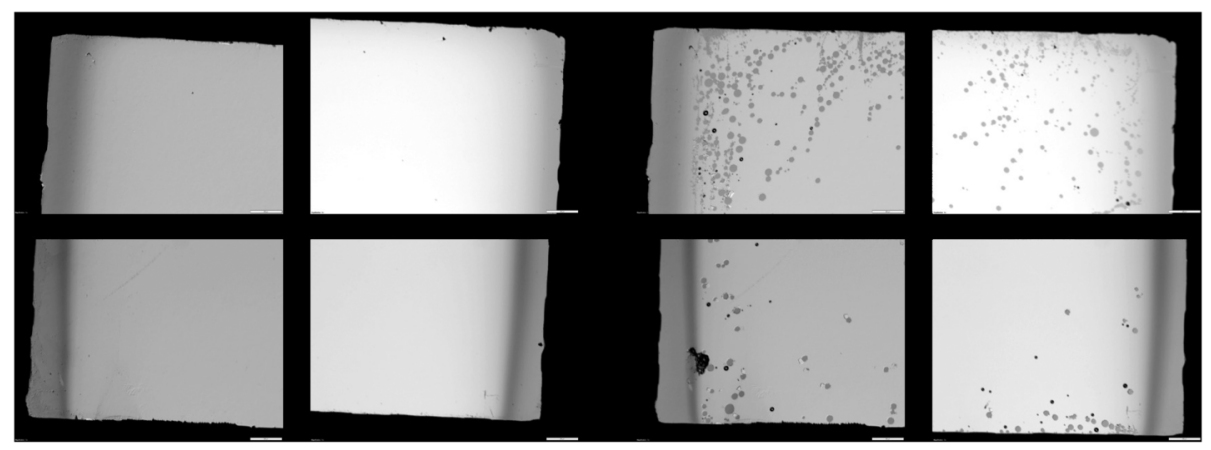

(a)

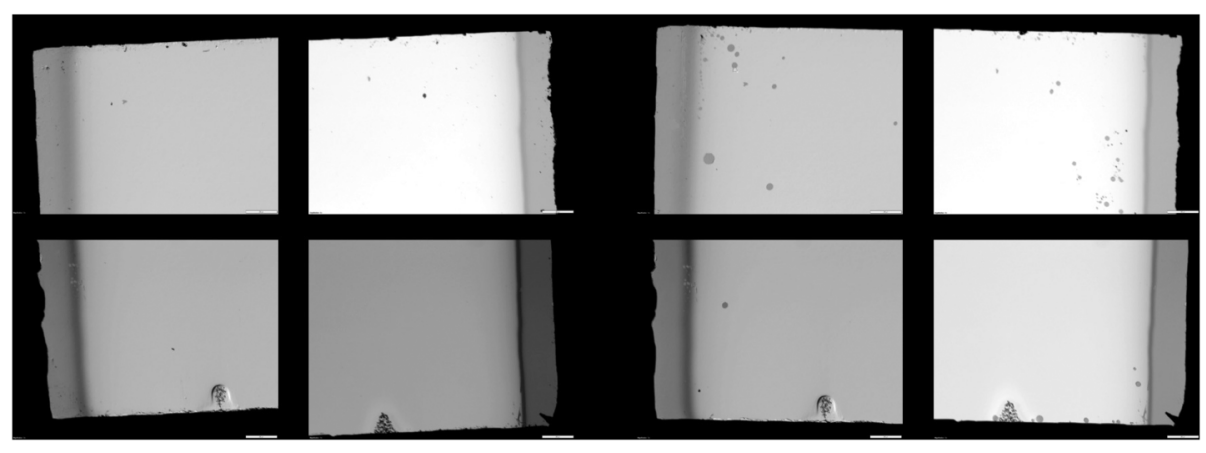

(b)

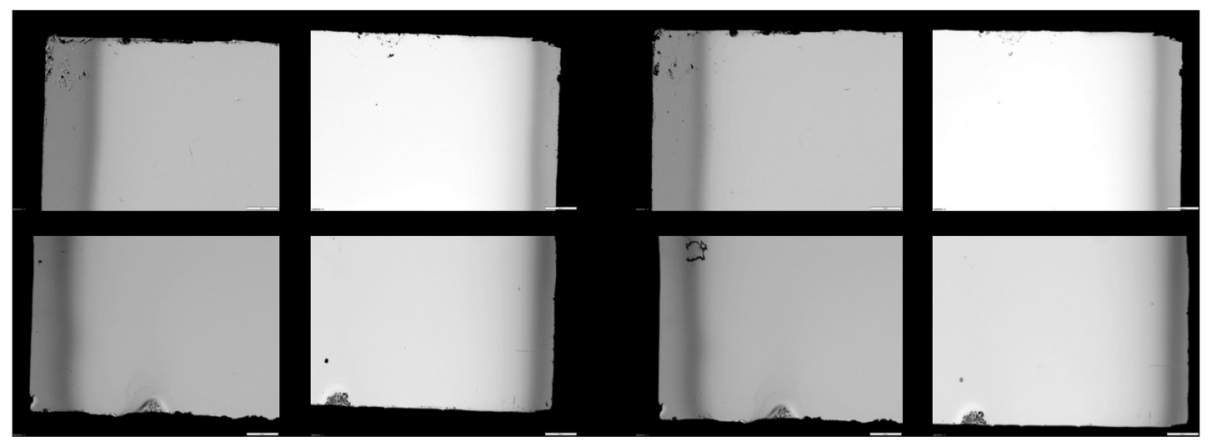

(c)
FIG. 2. Optical microscope images (magnification $\times 5$ ) of substrate corners. Each image shows about $1 \mathrm{~mm}$ in the vertical direction and $1.5 \mathrm{~mm}$ in the horizontal direction out of the $40.0 \times 65.7 \mathrm{~mm}^{2}$ substrate surfaces. (a) Substrate $714-10$, without plasma etching; (b) substrate 714-01, etched with $100 \mathrm{~W}$; and (c) substrate 714-07, etched with $450 \mathrm{~W}$. Left: before SC-1 cleaning. Right: after SC-1 cleaning. All substrates are non-patterned and coated with $10 \mathrm{~nm}$ of iridium. Fewer holes appear in the iridium film after the SC-1 clean as the discharge power increases. 
TABLE III. AFM and XRR results of two non-plasma-etched SPO plates (substrates 714-10 and 714-11) as well as four plasma etched SPO plates (substrates 714-01, 714-05, 714-07, and 714-08). All substrates are non-patterned, coated with $10 \mathrm{~nm}$ of iridium and have gone through an SC-1 clean. No significant difference in rms roughness or thickness of the iridium films is observed.

\begin{tabular}{|c|c|c|c|c|c|c|}
\hline Substrate id & $\begin{array}{l}\text { Discharge } \\
\text { power } \\
\text { (W) }\end{array}$ & $\begin{array}{l}\text { Exposure } \\
\text { time } \\
(\mathrm{s})\end{array}$ & $\begin{array}{c}\text { rms after iridium } \\
\text { coating }(\mathrm{nm}) \\
1 \times 1 \mu \mathrm{m}^{2}\end{array}$ & $\begin{array}{l}\text { rms after iridium } \\
\text { coating }(\mathrm{nm}) \\
20 \times 20 \mu \mathrm{m}^{2}\end{array}$ & $\begin{array}{l}\text { XRR fitted } \\
\text { thickness } \\
(\mathrm{nm})\end{array}$ & $\begin{array}{l}\text { XRR fitted rms } \\
\text { roughness } \\
(\mathrm{nm})\end{array}$ \\
\hline 714-10 & $\ldots$ & $\ldots$ & 0.27 & 0.23 & 10.1 & 0.29 \\
\hline 714-11 & $\ldots$ & $\ldots$ & 0.28 & 0.23 & $\ldots$ & $\ldots$ \\
\hline 714-01 & 100 & 120 & 0.24 & 0.24 & 10.2 & 0.29 \\
\hline 714-05 & 100 & 120 & 0.25 & 0.23 & $\ldots$ & $\ldots$ \\
\hline 714-07 & 450 & 120 & 0.25 & 0.23 & 10.2 & 0.32 \\
\hline 714-08 & 450 & 120 & 0.25 & 0.24 & $\ldots$ & $\ldots$ \\
\hline
\end{tabular}

ion bombardment with a mixture of argon and oxygen ions. The plasma discharge power and exposure time vary per substrate and are given in Table I along with the substrate identification string (id) and the measured rms surface roughness.

AFM measurements were performed in the center of each substrate with scan sizes of $1 \times 1 \mu \mathrm{m}^{2}$ and $20 \times 20 \mu \mathrm{m}^{2}$. The results obtained are reported in Table I and show that the rms roughness has decreased, but the change is not significant: $0.25 \pm 0.03 \mathrm{~nm}$ before plasma etching vs $0.22 \pm 0.01 \mathrm{~nm}$ after. The plasma etching intensity also has no significant effect on the rms roughness with the current condition.

\section{INVESTIGATING COATING STABILITY ON NON-PATTERNED SPO PLATES}

A $10.0 \mathrm{~nm}$ thick iridium layer (Table II) was deposited on two non-patterned (that is without photoresist), non-plasma-etched SPO plates (substrates 714-10 and 714-11) as well as four nonpatterned, plasma-etched SPO plates (substrates 714-01, 714-05, 714-07, and 714-08). The substrates underwent plasma etching with powers of $100 \mathrm{~W}$ and $450 \mathrm{~W}$ and were thereafter subjected to a wet chemical process (SC-1 cleaning) needed for direct bonding of plates in the complete SPO manufacturing process.

To determine if any damage to the iridium film occurred during the SC-1 clean, we took two sets of images with an optical microscope, one right after the iridium deposition and another after the SC-1 clean. The optical microscope images are presented in Fig. 2. The plasma etching effect is noticeable after the SC-1 clean. Indeed, for the non-plasma etched substrates (i.e., substrate 714-10), numerous holes appear in the iridium film after the SC-1 clean. The SPO plates plasma etched with a discharge power of $100 \mathrm{~W}$ (i.e., substrate 714-01) show an improvement (fewer holes). At a discharge power of $450 \mathrm{~W}$ (i.e., substrate 714-07), the plasma etching proved effective at preventing holes in the iridium film after the SC-1 clean. Note that the holes have a higher density at the edges of the plates.

Results of AFM measurements on the substrates are reported in Table III. The rms roughness of the sputtered iridium film on non-plasma-etched SPO plates (substrates 714-10 and 714-11, $0.25 \pm 0.03 \mathrm{~nm}$ ) is not significantly different from the rms roughness of the sputtered iridium film on plasma-etched SPO plates (714-01, 714-05, 714-07, and 714-08, $0.24 \pm 0.01 \mathrm{~nm})$.

To assess the impact of SC-1 cleaning on the iridium coating thickness, we also performed X-ray reflectivity (XRR) measurements at $8 \mathrm{keV}$ on the center of the substrates, where the hole density is low for all SPO plates. The data and the best fit models are shown in Fig. 3, and the best fit thicknesses and roughness are reported in Table III. For the different plasma etching parameters, no significant difference in rms roughness or thickness of the iridium films is observed.

We conclude that the thickness and the rms roughness of the sputtered iridium thin film are not impacted by plasma etching of the non-patterned SPO plates. Plasma etching does, however, affect the resistance of the coating to SC-1 cleaning, with the higher discharge power of $450 \mathrm{~W}$ yielding better results. The higher density of holes at the edges of the plates is attributed to handling of the

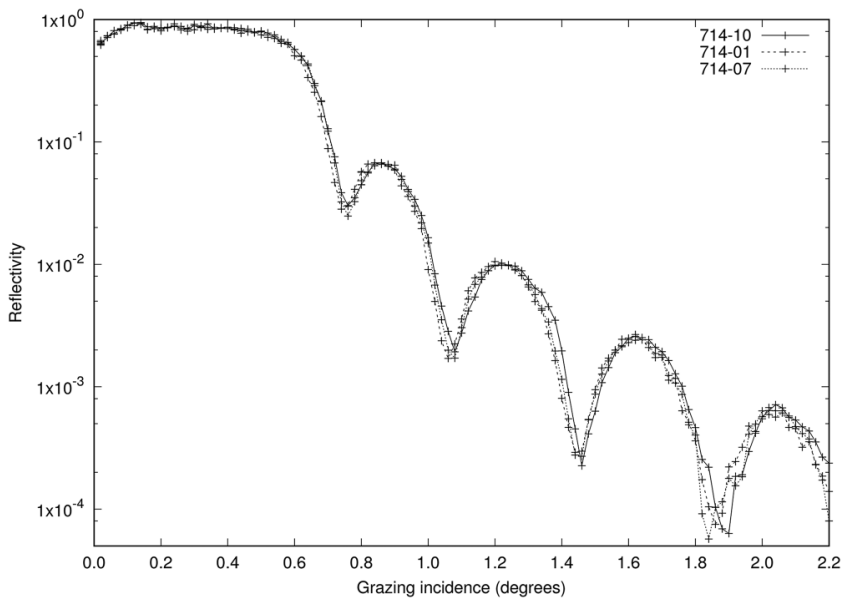

FIG. 3. Measured XRR of three SPO plates: substrate 714-10 (non-plasma etched), substrate 714-01 (etched with 100 W), and 714-07 (etched with $450 \mathrm{~W}$ ). All substrates are non-patterned, coated with $10 \mathrm{~nm}$ of iridium and have gone through an SC-1 clean. The rms roughness and thickness of the iridium films are not significantly different for the different plasma etching powers, resulting in similar XRR. 


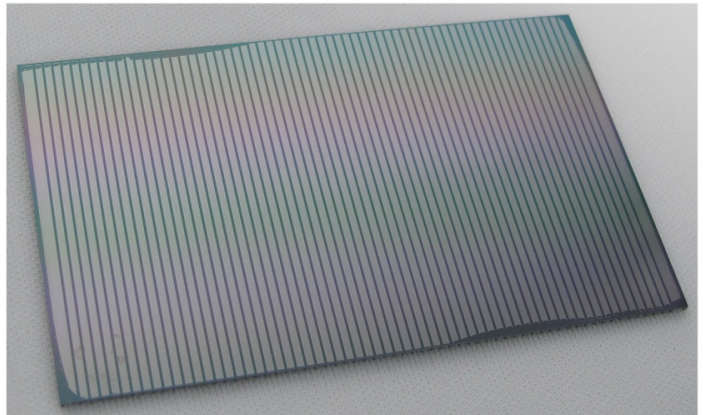

(a)

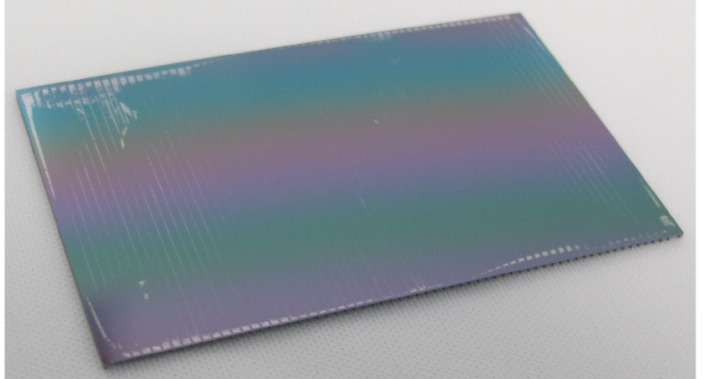

(b)

FIG. 4. Substrate 10005-15 (without plasma etching). Substrate dimensions are about $40.0 \times 65.7 \times 0.8 \mathrm{~mm}^{3}$. (a) After lift-off and (b) after SC-1 cleaning. The iridium coating has been unintentionally removed on most of the substrate surfaces.

mirror plates prior to coating; the plates are held on their edges, resulting in possible organic contamination in these areas.

\section{VALIDATING COATING STABILITY ON PATTERNED SPO PLATES}

The complete SPO manufacturing process includes coating deposition by sputtering thin films of metals onto the non-ribbed side, while a photoresist layer prevents the coating from depositing onto the bonding surfaces, enabling direct silicon bonding. This photoresist has a pattern matching the ribs on the backside of the plate (see Fig. 4). The photoresist is lifted-off chemically in a dimethyl sulfoxide (DMSO) bath after coating deposition and before SC-1 clean.

A layer of $10.0 \mathrm{~nm}$ of iridium was deposited on two patterned (with photoresist), non-plasma-etched SPO plates (substrates 10000-16 and 10005-15) as well as seven patterned, plasma-etched SPO plates (substrates 10008-04, 10008-05, 10008-07, 10008-12, 10008-06, 10002-12, and 10008-15). The discharge power of the plasma was $450 \mathrm{~W}$, and the exposure time was $240 \mathrm{~s}$. Subsequently, all substrates went through a lift-off process and then to the SC-1 clean.

Figures 4 and 5 show substrates 10005-15 (without plasma etching) and 10008-04 (with plasma etching) after lift-off (before the SC-1 clean) and after SC-1 cleaning. The iridium coating has been unintentionally removed on most of the surface of substrate 10005-15, which did not undergo plasma etching (see Fig. 4). This observation indicates the presence of residual photoresist on the entirety of the reflective side of the patterned SPO plate prior to coating deposition as seen in a previous study. ${ }^{13}$ However, the iridium coating is still present on substrate 10008-04, which underwent plasma etching (see Fig. 5), indicating that photoresist has been etched by the plasma prior to coating deposition.

In both cases though (with or without plasma etching), the iridium coating has been unintentionally removed along the edges of the reflective side of the substrates directly after lift-off. The pattern of this coating removal (edges only) supports the

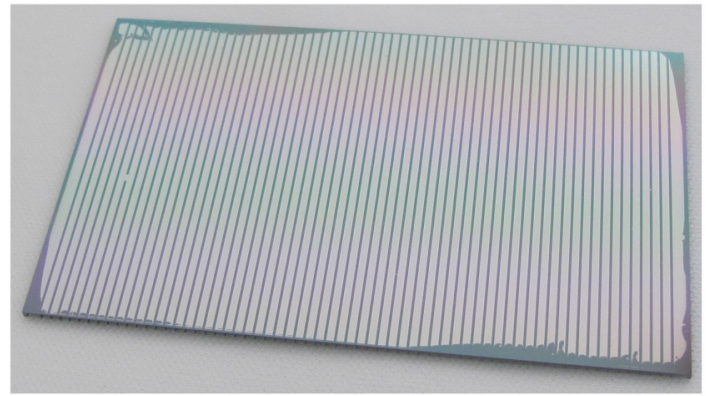

(a)

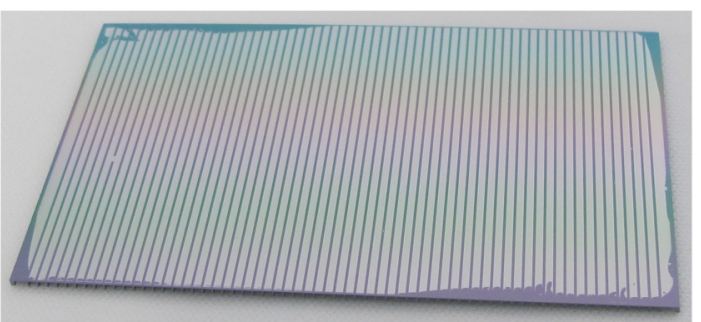

(b)

FIG. 5. Substrate 10008-04 (with plasma etching). Substrate dimensions are about $40.0 \times 65.7 \times 0.8 \mathrm{~mm}^{3}$. (a) After lift-off and (b) after SC-1 cleaning. The iridium coating is unaffected by the SC-1 clean based on visual inspection. 


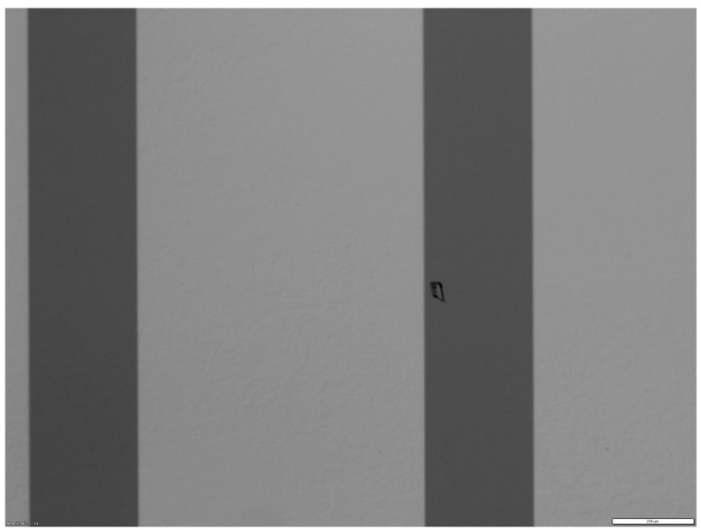

(a)

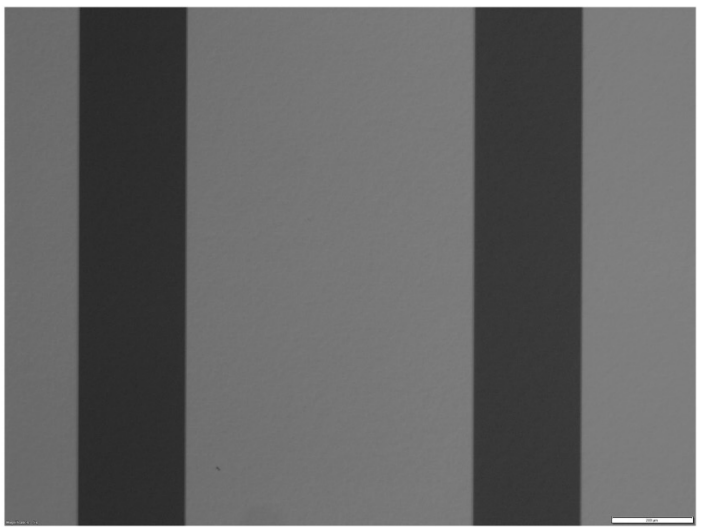

(b)

FIG. 6. Optical microscope images (magnification $\times 5$ ) of the surface of substrate 10008-04 (with plasma etching). (a) After lift-off and (b) after SC-1 cleaning. In both cases, the interfaces between iridium coating (light gray) and silicon oxide (dark gray, $270 \mu \mathrm{m}$ in the horizontal direction) are sharp, and no holes are observed in the coating.

hypothesis that photoresist residuals are present in these areas even after plasma etching.

There, the resist might be thicker due to edge effects during deposition by spin coating; thickness distribution should be examined, and other improved coating method such as spray coating should be considered.

Figure 6 shows optical microscope images (magnification $\times 5$ ) of the center of substrate 10008-04, which underwent plasma etching. The interfaces between iridium coating and silicon oxide are sharp, and no holes in the coating are observed. If present, the photoresist residuals on the coating areas (between the patterned stripes) have been etched away by the plasma prior to coating deposition.

\section{CONCLUSIONS AND DISCUSSION}

Plasma etching of SPO plate surfaces before thin film deposition prevents unintentional removal of the metallic coatings during SC-1 cleaning. This indicates that the substrates have photoresist residuals and/or organic contamination on the reflective side. Indeed, the plasma etching process performed by bombarding the SPO plate surface with a mixture of argon and oxygen ions would remove, if present, photoresist residuals and organic contamination by elastic scattering and/or chemical reactions. Most of the organic contamination and some of these residuals have been removed successfully by plasma etching with a discharge power of $450 \mathrm{~W}$ prior to coating deposition but not in the regions close to the edges. There, photoresist residuals might be thicker due to the spin coating deposition method used. We recommend to measure the thickness distribution of the photoresist layer and to consider spray coating. Also, it would be interesting to perform direct measurement of the organic contamination, for instance, by using $\mathrm{x}$-ray photoelectron spectroscopy.
It is also concluded that plasma etching and thin film deposition do not impact the surface rms roughness, allowing for low scattering and high imaging performance from the coated SPO plates.

Overall, this work demonstrates that plasma etching makes the metallic coating deposition process compatible with the SC-1 cleaning step needed for direct silicon bonding. This is essential to increase the effective area of SPO-based $\mathrm{x}$-ray telescopes such as Athena, to build complex shapes such as Wolter type-I that will survive launch and space flight conditions, and, therefore, to extend the breadth and scope of future astrophysical observations.

\section{ACKNOWLEDGMENTS}

The authors acknowledge the European Space Agency under whose funding (Contract No. 4000116080/15/NL/BW) this work was carried out.

\section{DATA AVAILABILITY}

The data that support the findings of this study are available from the corresponding author upon reasonable request.

\section{REFERENCES}

${ }^{1}$ A. V. Kravtsov and S. Borgani, Annu. Rev. Astron. Astrophys. 50, 353 (2012).

${ }^{2}$ Y. Li, L. Hernquist, B. Robertson, T. J. Cox, P. F. Hopkins, V. Springel, L. Gao, T. Di Matteo, A. R. Zentner, A. Jenkins, and N. Yoshida, Astrophys. J. 665, 187 (2007).

${ }^{3}$ M. C. Begelman, M. Volonteri, and M. J. Rees, Mon. Not. R. Astron. Soc. 370, 289 (2006)

${ }^{4}$ M. Volonteri and M. C. Begelman, Mon. Not. R. Astron. Soc. 409, 1022 (2010).

${ }^{5}$ M. Beijersbergen, S. Kraft, R. Günther, A. L. Mieremet, M. Collon, M. Bavdaz, D. H. Lumb, and A. J. Peacock, in UV and Gamma-Ray Space Telescope Systems, edited by G. Hasinger and M. J. L. Turner (SPIE, International Society for Optics and Photonics, 2004), Vol. 5488, pp. 868-874. 
${ }^{6}$ M. Bavdaz, E. Wille, M. Ayre, I. Ferreira, B. Shortt, S. Fransen, M. J. Collon, G. Vacanti, N. Barrière, B. Landgraf, R. Start, C. van Baren, D. D. M. Ferreira, S. Massahi, F. Christensen, M. Krumrey, V. Burwitz, G. Pareschi, G. Valsecchi, P. Oliver, A. Seidel, and T. Korhonen, in Optics for EUV, X-Ray, and Gamma-Ray Astronomy IX, edited by S. L. O'Dell and G. Pareschi (SPIE, International Society for Optics and Photonics, 2019), Vol. 11119, pp. 71-82.

${ }^{7}$ M. J. Collon, G. Vacanti, N. M. Barrière, B. Landgraf, R. Günther, M. Vervest, L. Voruz, S. Verhoeckx, L. Babić, L. Keek, D. Girou, B. Okma, E. Hauser, M. W. Beijersbergen, M. Bavdaz, E. Wille, S. Fransen, B. Shortt, I. Ferreira, J. Haneveld, A. Koelewijn, R. Start, M. Wijnperle, J.-J. Lankwarden, C. van Baren, P. Hieltjes, J. W. den Herder, P. Müller, E. Handick, M. Krumrey, M. Bradshaw, V. Burwitz, G. Pareschi, S. Massahi, S. Svendsen, D. D. M. Ferreira, F. E. Christensen, G. Valsecchi, P. Oliver, I. Chequer, and K. Ball, in Optics for EUV, X-Ray, and Gamma-Ray Astronomy IX, edited by S. L. O'Dell and G. Pareschi (SPIE, International Society for Optics and Photonics, 2019), Vol. 11119, pp. 150-157.

${ }^{8}$ M. Shimbo, K. Furukawa, K. Fukuda, and K. Tanzawa, J. Appl. Phys. 60, 2987 (1986).

${ }^{9}$ W. P. Maszara, G. Goetz, A. Caviglia, and J. B. McKitterick, J. Appl. Phys. 64, 4943 (1988).

${ }^{10} \mathrm{H}$. Wolter, Ann. Phys. 445, 94 (1952).

${ }^{11}$ D. D. M. Ferreira, F. E. Christensen, A. C. Jakobsen, N. J. Westergaard, and B. Shortt, in Space Telescopes and Instrumentation 2012: Ultraviolet to Gamma
Ray, edited by T. Takahashi, S. S. Murray, and J.-W. A. den Herder (SPIE, International Society for Optics and Photonics, 2012), Vol. 8443, pp. 1601-1611. ${ }^{12}$ W. Kern, RCA Rev. 31, 187 (1970).

${ }^{13}$ S. Massahi, D. A. Girou, D. D. M. Ferreira, F. E. Christensen, A. C. Jakobsen, B. Shortt, M. Collon, and B. Landgraf, in Optics for EUV, X-Ray, and Gamma-Ray Astronomy VII, edited by S. L. O'Dell and G. Pareschi (SPIE, International Society for Optics and Photonics, 2015), Vol. 9603, pp. 155-165.

${ }^{14}$ S. Massahi, F. E. Christensen, D. D. M. Ferreira, A. Jafari, S. Svendsen, P. L. Henriksen, B. Shortt, I. Ferreira, M. Bavdaz, M. Collon, B. Landgraf, D. Girou, A. Langer, W. Schönberger, T. Wellner, M. Krumrey, and L. Cibik, in Optics for EUV, X-Ray, and Gamma-Ray Astronomy IX, edited by S. L. O'Dell and G. Pareschi (SPIE, International Society for Optics and Photonics, 2019), Vol. 11119, pp. 91-106.

${ }^{15}$ S. C. Vitkavage and E. A. Irene, J. Appl. Phys. 64, 1983 (1988).

${ }^{16}$ R. Pétri, P. Brault, O. Vatel, D. Henry, E. André, P. Dumas, and F. Salvan, J. Appl. Phys. 75, 7498 (1994).

17. Stover, Optical Scattering: Measurement and Analysis, Press Monographs (SPIE Press, 2012).

${ }^{18}$ D. Spiga, G. Cusumano, and G. Pareschi, in Optics for EUV, X-Ray, and Gamma-Ray Astronomy III, edited by S. L. O’Dell and G. Pareschi (SPIE, 2007), Vol. 6688, p. $66880 \mathrm{H}$

${ }^{19}$ D. Spiga, in Optics for EUV, X-Ray, and Gamma-Ray Astronomy III, edited by S. L. O’Dell and G. Pareschi (SPIE, 2007), Vol. 6688, p. 66880K. 